\title{
Adsorption of Manganese(II) Ion in the Water Phase by Citric Acid Activated Carbon of Rice Husk
}

\author{
Suhendrayatna, Muhammad Zaki, Annisa Delima Habdani Harahap \\ and Fitriani Verantika \\ Faculty of Engineering, Department of Chemical Engineering, Syiah Kuala \\ University, Banda Aceh, Indonesia
}

\begin{abstract}
Purpose - In this study, the possibility of the application of rice husks for adsorbing Mn(II) ion in the water phase has been studied.

Design/Methodology/Approach - Experimental studies have been initiated by preparing activated carbon from rice husks. The activation of rice husks was done using both physical and chemical treatment methods through heating at $110{ }^{\circ} \mathrm{C}$ and washing with citric acid activator at $0.2 \mathrm{M}, 0.4 \mathrm{M}$, and $0.6 \mathrm{M}$. The adsorption tests were conducted as two part tests: preliminary and primary. The preliminary test was conducted to choose the best condition of four independent variables, i.e., contact time (0-120 minutes), activator concentrations $(0.2,0.4$, and $0.6 \mathrm{M})$, initial $\mathrm{Mn}$ (II) concentrations $(10,20,50,100,200$, and $400 \mathrm{mg} / \mathrm{L})$, and adsorption temperatures $\left(30,47\right.$, and $\left.67^{\circ} \mathrm{C}\right)$.

Findings - By identifying the substituted groups using Fourier Transform Infrared Spectroscopy after activation with citric acid, it was found that the highest transmittance percentage was present in activated carbon with $0.2 \mathrm{M}$ of citric acid. The best adsorption capacity and efficiency was $13.87 \mathrm{mg} / \mathrm{g}$ and $79.60 \%$, respectively, which were obtained at $200 \mathrm{mg} / \mathrm{L}$ initial concentration with a $0.2 \mathrm{M}$ citric acid concentration for 120 min contact time at $47^{\circ} \mathrm{C}$. These results lead to a conclusion that rice husks after activation with citric acid can be applied as an adsorbent for Mn(II) adsorption in the water phase.
\end{abstract}

Research Limitations/Implications - The activated carbon produced was only applicable for the adsorption of Mn(II) ions from the water phase, but not applicable for the adsorption of other heavy metals ions.

Practical Implications - Rice husks were potentially prepared as an adsorbent for Mn(II) ion adsorption in the water phase that was low cost, environmental friendly, and easy to prepare.

Originality/Value - Activated carbon prepared from biomass was mostly carried out using acids at high concentrations while the study was conducted using weak acids (citric acid) at low concentrations.

Keywords Adsorption, $\mathrm{Mn}(\mathrm{II})$, citric acid, rice husk

All papers within this proceedings volume have been peer reviewed by the scientific committee of the Malikussaleh International Conference on Multidisciplinary Studies (MICoMS 2017).

(c) Suhendrayatna, Muhammad Zaki, Annisa Delima Habdani Harahap, Fitriani Verantika. Published in the Emerald Reach Proceedings Series. Published by Emerald Publishing Limited. This article is published under the Creative Commons Attribution (CC BY 4.0) licence. Anyone may reproduce, distribute, translate and create derivative works of this article (for both commercial and noncommercial purposes), subject to full attribution to the original publication and authors. The full terms of this licence may be seen at http://creativecommons.org/licences/by/4.0/legalcode

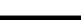

- 


\section{Proceedings of 1 . Introduction}

MICoMS 2017 In environmental studies, manganese (Mn) is one of the predominant elements that participate in oxidation-reduction process together with oxygen, nitrogen, carbon, iron, and sulfur. This metal occurs in insoluble forms, i.e., colloidal and particulate $\mathrm{MnO}_{2}$, which serves as a scavenger for trace metals ions and mainly exists in as manganese(IV), which is a dominant chemical species. However, manganese(II) ion is often linked with water pollution, especially in closed water areas, such as ponds, and is rather stable in anoxic water phase environments (Okumura et al., 2002). The presence of Mn ions in groundwater is usually accompanied with iron ions released from soils and rocks. These ions are essential for humans but are also toxic. The presence of these ions in water can be detected in laboratories and can also be recognized organoleptically.

In recent years, the use of biomass adsorption techniques for the removal of environmental substances has increased because they are safe and easy to use. Patil et al. (2016) had reported the application of Mn removal technologies, such as oxidation or filtration (degree of $\mathrm{Mn}$ (II) shifting 95\%), chemical precipitation (degree of $\mathrm{Mn}$ (II) ions recovery $99.5 \%$ ), and adsorption (Mn(II) removal degree up to $99.42 \%$ ), both in wastewater and freshwater.

Rice husks are the hard protective coverings of grains of rice, which are made of lignin and silica, to protect grains during the growing season. Rice husk biomass plays an important role in the adsorption process because of the wide range of the pore size of rice husks. The pore size can be enlarged and adapted to the molecular size of metals ions in the water phase during the activation process, so that the metal ions can easily enter into the pore of the adsorbent. In recent years, some researchers have proposed other biomasses to absorb metal ions, including paddy straw, tea biomass (Amarasinghe and Williams, 2007), coffee biomass (Rossner et al., 2009), and other adsorbents (Bhattacharya et al., 2008). Chemically, rice husks can be activated with some acid to increase the adsorption capacity of metal ions. Through the interaction with the metal oxidator in the water phase, the adsorption capacity can be increased (Marshall et al., 1999). The activation process of solid waste materials at a high temperature with some acids such as tartaric acid, phosphoric acid, and citric acid can increase the adsorption capacity of the metal ions (Marshall et al., $2000,2001)$. During the activation process, some of the acid groups occur and form ester groups (Marshall et al., 2001).

The purpose of this study was to evaluate the ability of rice husks after being activated using citric acid in absorbing Mn(II) ions in the water phase. This study was conducted as batch mode experiments and run with three independent variables, i.e., contact time $(0-120$ minutes), activator concentration ( $0.2,0.4$, and $0.6 \mathrm{M}$ ), and initial $\mathrm{Mn}$ (II) concentrations (10, 20, 50, 100, 200, and $400 \mathrm{mg} / \mathrm{L}$ ), to obtain $\mathrm{Mn}(\mathrm{II})$ adsorption isotherms and kinetics parameters.

\section{Materials and method}

\subsection{Materials and equipment}

Rice husks with particle size of 25-40 mesh were obtained from a paddy field in Aceh Besar District, and chemicals such as citric acid $\left(\mathrm{C}_{6} \mathrm{H}_{8} \mathrm{O}_{7}\right)$ and a solution of manganese $\left(\mathrm{MnSO}_{4}\right.$. $\mathrm{H}_{2} \mathrm{O}$, ion source) were obtained commercially from Waco Chemicals, Inc. The experimental equipments used were tube furnace (LabHouse), glassware (Pyrex), oven dryer (ISUZU DSL1000), analytical balance (Sartorius), planetary ball mill (NBI), desiccator (Pyrex), atomic absorption spectrometer (AAS, Shimadzu AA-6300), Fourier transform infrared spectrometer (FTIR, Shimadzu Prestige 21), and sieve shaker (Biostat). 


\subsection{Research procedure}

2.2.1. Biomass preparation. To remove dust, the rice husks were washed with distilled water several times, soaked in hot water for 1 hour, and dried in an oven dryer at $30^{\circ} \mathrm{C}$ for 5 hours and again at $110^{\circ} \mathrm{C}$ for 1 hour. The dried rice husks were then milled with a ball mill and sieved on the size of $25-40$ mesh. Finally, the rice husks were dried again at $110^{\circ} \mathrm{C}$ for 3 hours and kept in a desiccator before use. The hydroxyl content in the biomass was examined using FTIR.

2.2.2. Biomass activation. One gram of rice husk was dissolved in different

Adsorption of Manganese concentrations of citric acid $(0.2 \mathrm{M}, 0.4 \mathrm{M}$, and $0.6 \mathrm{M})$ to remove the silicates and lignin in the rice husks to enable better adsorption. Citric acid enters into the cellulose structure and acts as a chelating agent during activation process. Citric acid is an organic acid that has carboxyl groups, tends to donate protons $\left(\mathrm{H}^{+}\right)$, and forms negatively charged carboxyl group, which is capable of configuring stable complexes with several ions (Faizul et al., 2013). During activation, the presence of citric acid will configure a few new sites on the surface of the adsorbent, which will increase the adsorption capacity. The mixture of rice husks and citric acid was then stirred at $100 \mathrm{rpm}$ for 2 hours at room temperature. The activated rice husks were then washed with distilled water repeatedly until a $\mathrm{pH}$ of \pm 7 , and then dried at $50^{\circ} \mathrm{C}$ for 24 hours (Marshall et al., 2000). The hydroxyl content in the rice husk biomass was examined using FTIR to determine the increase in hydroxyl groups.

2.2.3. Adsorption. One gram of the activated rice husks was made to contact with 250 $\mathrm{mL}$ of $\mathrm{MnSO}_{4} \cdot \mathrm{H}_{2} \mathrm{O} 200 \mathrm{mg} / \mathrm{L}$ at a speed of $100 \mathrm{rpm}$ for different time periods $(0-120$ minutes) at different temperatures $\left(30,47\right.$, and $\left.67{ }^{\circ} \mathrm{C}\right)$. After the adsorption process was completed, the concentration of $\mathrm{Mn}$ (II) ions in the water phase was analyzed by AAS in accordance with SNI 06-6989-4-2004 at a wavelength of $279.3 \mathrm{~nm}$. The above treatment was repeated for $\mathrm{Mn}$ (II) concentrations at 10, 20,50,100, and $400 \mathrm{mg} / \mathrm{l}$ and at temperatures of 47 and $67^{\circ} \mathrm{C}$. Before and after activation, the samples were analyzed using FTIR at the range of infrared wavelength at $400-4,000 \mathrm{~cm}^{-1}$. The samples ( $5 \%$ by weight) were homogenized with $95 \%$ of $\mathrm{KBr}$ as the background in the analysis of powder samples.

\section{Results and discussion}

\subsection{Effect of citric acid activation on the functional group of activated carbon}

The effect of citric acid on the activation of rice husks was analyzed using FTIR. The functional groups of the activated carbon was obtained using the spectra of FTIR in the range of $400-4,000 \mathrm{~cm}^{-1}$, as shown in Figure 1.

Figure 1 shows the functional group differences of each activated carbon and peak possessed by each activated carbon, which can maximize the absorption performance of Mn metal ions in this study. Rice husks without activation have a smaller absorption area with a small percentage of transmittance. The activation of rice husks with citric acid enables a higher adsorption area and higher transmittance percentage than those without activation. The activation with $0.2 \mathrm{M}$ citric acid has a larger $\mathrm{O}-\mathrm{H}$ functional group with higher transmittance than activation with other citric acid activated carbon. It was observed that the adsorbent has an $\mathrm{O}-\mathrm{H}$ functional group as observed by changing of wavelength absorption at $3,555 \mathrm{~cm}^{-1}$ and the group of $\mathrm{C}=\mathrm{C}$ indicated at the wavelength of $1,718 \mathrm{~cm}^{-1}$. Furthermore, at the wavelength of $1,050-1,300 \mathrm{~cm}^{-1}$, the absorbent indicated that there was a $\mathrm{C}-\mathrm{O}$ group with a higher transmittance percentage. The functional groups presented in each of the adsorbents did not a show significant growing number of carbonyl groups but showed a significant percentage of transmittance. By identifying the groups presented in each of the adsorbents, it can be seen that the highest transmittance percent was present in the activated carbon with $0.2 \mathrm{M}$ of citric acid. 
Proceedings of
MICoMS 2017

\section{0}

Figure 1.

Wavelength of FTIR Spectra for the Adsorbent

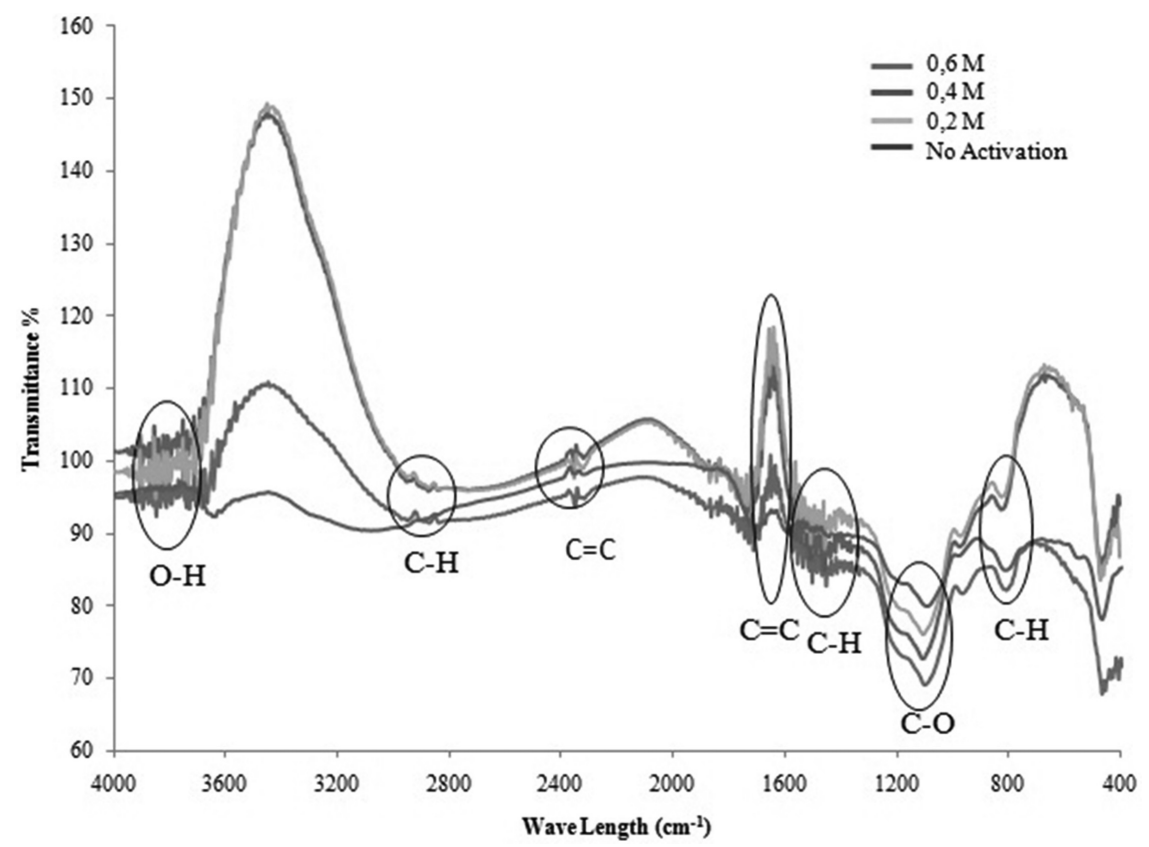

3.2. Determination of equilibrium adsorption time of $M n$ (II) during the preliminary test

Preliminary tests were conducted by varying contact times to evaluate the influence of equilibrium time on the adsorption of $\mathrm{Mn}$ (II) ion by the activated rice husks. The equilibrium time is the time when there is no more absorption of substances into the absorbent medium. The variation of contact time performed on this test was $0,10,20,40,60,80,100$, and 120 minutes, and the result is shown in Figure 2.

The absorption capacity is the amount of metal ions in milligrams (mg) that can be adsorbed together with the adsorbent mass in grams. Figure 2 shows that the contact time of 100 and 120 minutes has a similar absorption capacity of 13.72 and $13.77 \mathrm{mg} / \mathrm{g}$, respectively. This condition shows that the adsorption capacity was toward the equilibrium point. The influence of contact time occurs when the adsorption process has not reached the equilibrium time (Makinde et al., 2007). At a longer contact time, the adsorption of Mn(II) ions were increased until it reaches the equilibrium time. These results indicated that the optimum contact time occurred at 120 minutes, since in 120 minutes it no longer showed a significant increase in absorption capacity. The same result was also found by Mariana et al., (2015) and Makinde et al. (2007). Furthermore, Figure 2 shows that the absorption efficiency at each contact time was $10.68,24.09,49.33,65.45,73.45,78.77$, and $79.01 \%$. From these data, it can be seen that in 100-120 minutes the difference in absorption efficiency was found to be optimal. The absorption efficiency tends to stabilize in the time leading to the equilibrium time. The long contact time causes the empty space on the adsorbent to be filled, and it will be difficult for the adsorbate to occupy the empty space. This causes the quantity of $\mathrm{Mn}$ (II) ions adsorbed on the activated carbon to be relatively low as it goes to the equilibrium point. This test indicated that the optimum contact time occurred at 120 minutes. 


\subsection{Influence of citric acid concentration on the adsorption capacity and efficiency}

To determine the best citric acid (as activator) concentration used to generate the activated carbon from rice husks, the adsorption test was performed using activated carbon with different citric acid concentrations of $0.2 \mathrm{M}, 0.4 \mathrm{M}$, and $0.6 \mathrm{M}$ with an initial concentration of the $\mathrm{Mn}$ (II) ion at $200 \mathrm{mg} / \mathrm{L}$ and the results are tabulated in Table 1 . The absorption capacity was found to be $13.77,13.74$, and $13.73 \mathrm{mg} / \mathrm{g}$, respectively. The results concluded that the best absorption capacity of $\mathrm{Mn}$ ion was found at a concentration of $0.2 \mathrm{M}$. The concentration of citric acid also influenced the adsorption efficiency. The adsorption efficiency at a citric acid concentration of $0.2,0.4$, and $0.6 \mathrm{M}$ was found $79.01 \%, 78.87 \%$, and $78.76 \%$, respectively. Similar to the absorption capacity, the highest absorption efficiency was obtained using citric acid activator with a concentration of $0.2 \mathrm{M}$.

\subsection{Influence of initial Mn(II) concentration on the adsorption capacity and efficiency}

The effect of initial Mn(II) concentration on the adsorption capacity and efficiency using activated carbon from rice husks is shown in Figure 3. Figure 3 shows that with the greater initial concentration on the water surface, the absorption capacity tends to increase. However, at concentrations of 200 and $400 \mathrm{mg} / \mathrm{L}$, the absorption capacity shows an insignificant increase, with the values of 13.77 and $14.21 \mathrm{mg} / \mathrm{g}$, respectively. Furthermore, it can be seen that with a higher concentration of adsorbate, the absorption efficiency tends to

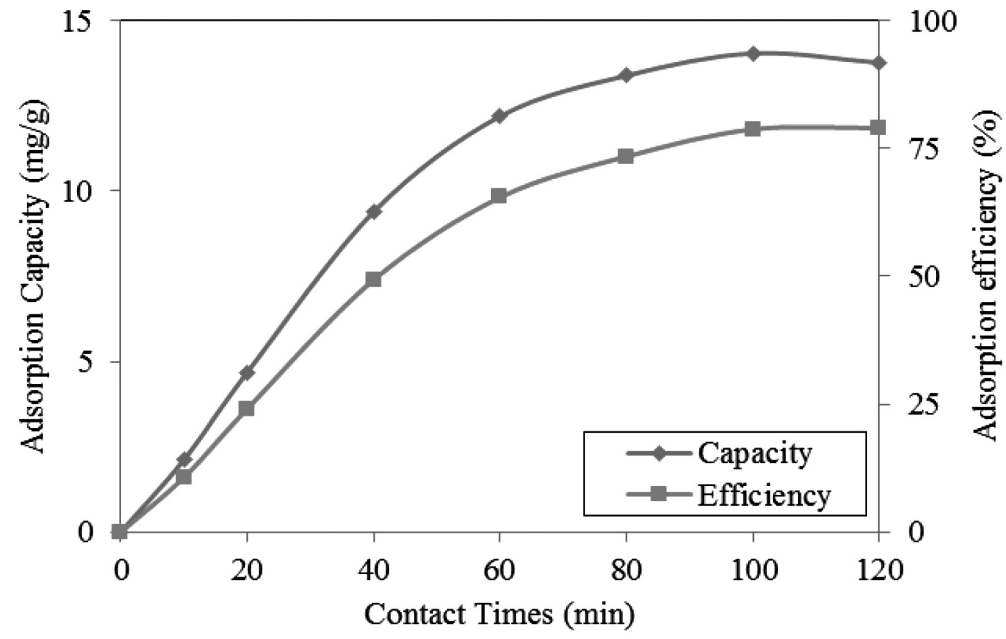

Figure 2.

Relationship of Contact Time on the Absorption Capacity (mg/g) of Mn Ion and Its Absorption Efficiency (\%) (Mn Initial Concentration

$200 \mathrm{mg} / \mathrm{L}$ with 0.2

Citric Acid and 100 rpm at $30^{\circ} \mathrm{C}$ )

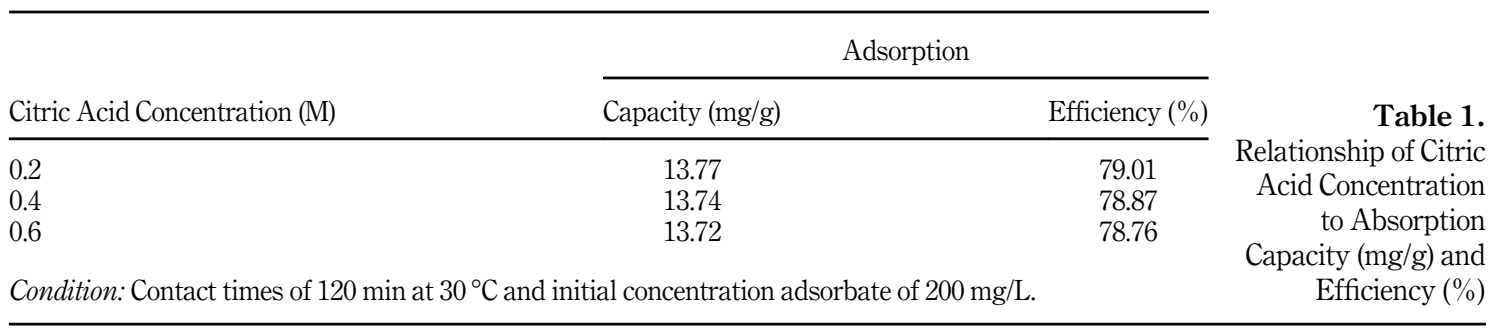


Proceedings of MICoMS 2017

\section{2}

Figure 3.

Relation of Initial Mn (II) Concentration on the Absorption Capacity $(\mathrm{mg} / \mathrm{g})$ and Efficiency $(\%)$ (Contact Time of 120 Citric Acid and 100 $\operatorname{rpm}$ at $30^{\circ} \mathrm{C}$ ) Minutes with 0.2

increase. In contrast to the discussion of the influence of the initial concentration of adsorbate on the absorption capacity, the absorption efficiency indicated that a significant decrease in the absorption efficiency occurred at a concentration of $400 \mathrm{mg} / \mathrm{L}$ of the adsorbate. This result indicated that activated carbon was no longer able to absorb Mn(II) at a concentration of $400 \mathrm{mg} / \mathrm{L}$. These results lead to a conclusion that the initial concentration of the adsorbate was found at a concentration of $200 \mathrm{mg} / \mathrm{L}$.

\subsection{Influence of temperature on the absorption capacity and efficiency}

Increasing and decreasing of temperature is one of the factors that can influence the adsorption. To determine the influence of temperature on the adsorption capacity and efficiency of the rice husk activated carbon, the adsorption process was conducted with the an $\mathrm{Mn}$ (II) concentration of $200 \mathrm{mg} / \mathrm{L}$ at the temperature variation of $30^{\circ} \mathrm{C}, 47^{\circ} \mathrm{C}$, and $67^{\circ} \mathrm{C}$, and the results are tabulated in Table 2 . The results show that the adsorption capacity increases with increasing temperature. The increase in temperature at the time of adsorption will cause the pores of the adsorbent to open followed by an increase in its absorption. The absorption capacity at temperatures 30,47 , and $67^{\circ} \mathrm{C}$ was found to be $13.77,13.87$, and 16.79 $\mathrm{mg} / \mathrm{g}$, respectively. It can be seen that the best temperature was obtained at the temperature of $47^{\circ} \mathrm{C}$. Overheating results in damaging of the structure of the adsorbent which causes a decrease in the absorption rate at $67^{\circ} \mathrm{C}$, which decreased absorption and resulted in desorption. According to Mariana et al. (2015), the adsorbate will be separated from the surface and pores of the adsorbent linear to the increasing temperature. Increasing

Table 2.

Relationship of Citric Acid Concentration to Absorption Capacity $(\mathrm{mg} / \mathrm{g})$ and Efficiency $(\%)$

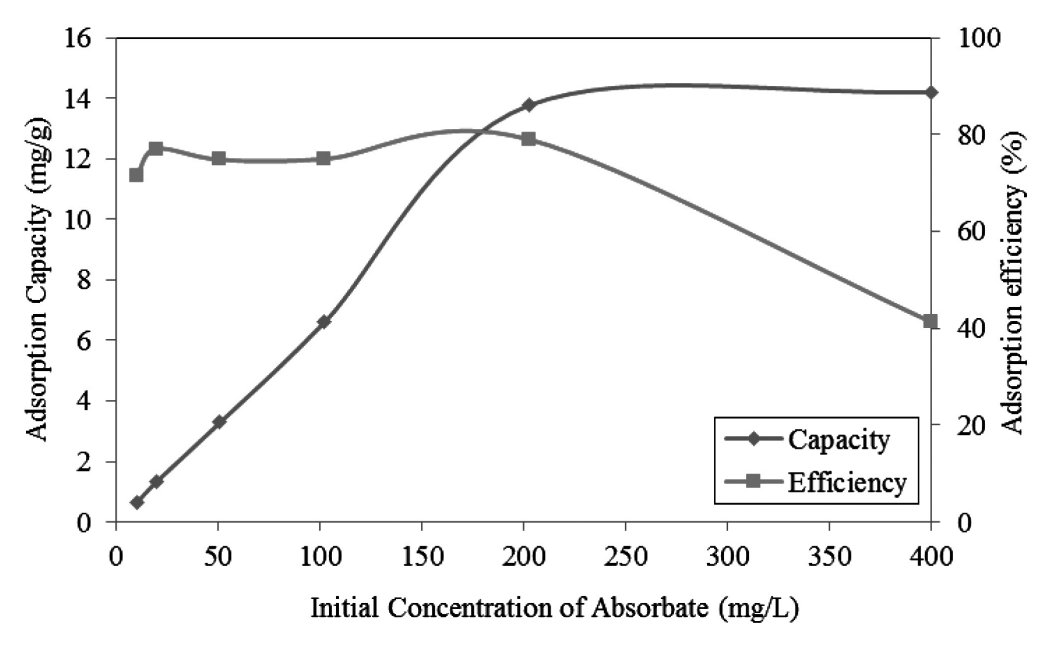

Adsorption

\begin{tabular}{lcc}
\cline { 2 - 3 } Temperature $\left({ }^{\circ} \mathrm{C}\right)$ & Capacity $(\mathrm{mg} / \mathrm{g})$ & Efficiency $(\%)$ \\
\hline 30 & 13.77 & 79.01 \\
47 & 13.87 & 79.60 \\
67 & 13.79 & 79.13 \\
\hline
\end{tabular}


temperatures also cause an increase in the desorption process, resulting in a decrease in the ability of adsorption. According to the results provided by Makinde et al. (2007), the increase in the temperature causes greater desorption. This happens because during physical adsorption, adsorption decreases with increasing temperature. Furthermore, the best adsorption efficiency was found at a temperature of $47^{\circ} \mathrm{C}$. The absorption efficiency at temperatures of 30,47 , and $67{ }^{\circ} \mathrm{C}$ were found to be $79.01 \%, 79.60 \%$, and $79.13 \%$, respectively. From these results, the best temperature was obtained at a temperature of $47^{\circ} \mathrm{C}$.

Adsorption of Manganese

\subsection{Influence of contact time on optimum conditions to the absorption capacity and efficiency}

After a number of tests were performed, the optimum absorption condition was obtained at an initial adsorbate concentration of $200 \mathrm{mg} / \mathrm{L}$ with an activator concentration of $0.2 \mathrm{M}$ citric acid at $47^{\circ} \mathrm{C}$. Then, based on these optimum conditions, the absorption process was performed by varying the contact time at $0,10,20,40,60,80,100$, and 120 minutes.

Figure 4 shows that with a longer contact time in the Mn absorption process by the activated carbon, the absorption capacity and efficiency also increases. However, the absorption capacity and efficiency at a contact time of 100 and 120 minutes showed no significant improvement, because the equilibrium was reached at 120 minutes. The highest absorption capacity occurred at 120 minutes with the absorption capacity of $13.87 \mathrm{mg} / \mathrm{g}$, while the adsorption efficiency occurred at $79.60 \%$.

\section{Conclusions}

Rice husk biomass after activation with citric acid can be applied as an adsorbent for Mn(II) adsorption from the water phase. By identifying the substituted groups with FTIR after activation with citric acid, it can be seen that the highest transmittance percent was present in the activated carbon with $0.2 \mathrm{M}$ of citric acid. The best adsorption capacity and efficiency was $13.87 \mathrm{mg} / \mathrm{g}$ and $79.60 \%$, respectively, which were obtained at an initial concentration of $200 \mathrm{mg} / \mathrm{L}$ with $0.2 \mathrm{M}$ citric acid for $120 \mathrm{~min}$ contact time at $47^{\circ} \mathrm{C}$.

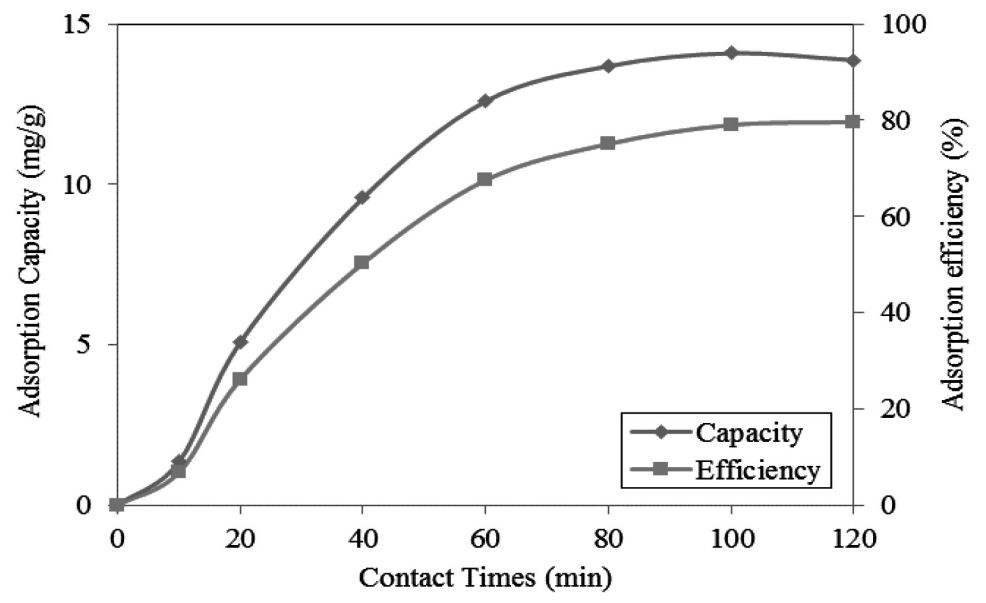

Figure 4 . Relation of Contact Time to the Absorption Capacity $(\mathrm{mg} / \mathrm{g})$ and Efficiency

$(\%)$ (Initial

Concentration 200 $\mathrm{mg} / \mathrm{L}$ with 0.2 Citric Acid and $100 \mathrm{rpm}$ at $\left.47^{\circ} \mathrm{C}\right)$ 


\section{Proceedings of References}

MICoMS 2017 Amarasinghe, B. and Williams, R.A. (2007). "Tea Waste as a Low Cost Adsorbent for the Removal of $\mathrm{Cu}$ and $\mathrm{Pb}$ from Wastewater". Chemical Engineering Journal, Vol. 132, pp. 299-309.

Bhattacharya, A.K., Naiya, T.K., Mandal, S.N. and Das, S.K. (2008). "Adsorption, Kinetics and Equilibrium Studies on Removal of Cr(VI) from Aqueous Solutions using Different Low-Cost Adsorbents". Chemical Engineering Journal, Vol. 137, pp. 529-541.

Faizul, C.P., Abdullah, C. and Fazlul, B. (2013). "Extraction of Silica from Palm Ash via Citric Acid Leaching Treatment”. Advances in Environmental Biology, Vol. 7, No. 12, pp. 3690-3695.

Makinde, W.O., Adetunji, G.J., Oladipo, A.A. and Adekunle, A.S. (2007). "Biomaterial Development for Industrial Waste Management". Electronic Journal of Environment Agricultural and Food Chemistry, Vol. 6, pp. 2120-2129.

Marshall, W.E., Chatters, A.Z., Wartelle, L.H. and McAloon, A. (2001). "Optimization and Estimated Production Cost of a Citric Acid-Modified Soybean Hull Ion Exchanger". Industrial Crops and Products, Vol.14, pp. 191-199.

Marshall, W.E., Wartelle, L.H., Boler, D.E., Johns, M.M. and Toles, C.A. (1999). "Enhanced Metal Absorption by Soybean Hulls Modified with Citric Acid”. Bioresource Technology, Vol. 69, pp. 263-268.

Marshall, W.E., Wartelle, L.H., Boler, D.E. and Toles, C.A. (2000). "Metal Ion Absorption by Soybean Hulls Modified with Citric Acid: A Comparative Study”. Environmental Technology, Vol. 21, pp. 601-607.

Mariana, F., Muslim, A., Alam, P.N. and Mariana. (2015). "Adsorption of Pb (II) Heavy Metals from Wastewater Using Modified Rice Husk as Adsorbent". In Proceedings of the 5th Annual International Conference of the Syiah Kuala University, pp. 12-16.

Okumura, M., Anate, T., Fujinaga, K. and Seike, Y. (2002). "A Simple and Rapid In Situ Preconcentration Method Using Solid-Phase Extraction for the Determination of Dissolved Manganese in Brackish Lake Water Samples”. Analytical Science, Vol. 18, pp. 1093-1097.

Patil, D.S., Chavan, S.M. and Oubagaranadin, J.U.K. (2016). "A Review of Technologies for Manganese Removal from Wastewaters”. Journal of Environmental Chemical Engineering, Vol. 4, pp. 468-487.

Rossner, A., Snyder, S.A. and Knappe, D.R.U. (2009). "Removal of Emerging Contaminants of Concern by Alternative Adsorbents". Water Research, Vol. 43, pp. 3787-3796.

\section{Corresponding author}

Suhendrayatna can be contacted at suhendrayatna@unsyiah.ac.id 